\title{
La resistencia desde el exilio: Chile y la revista España Libre
}

\author{
Yasmina YOUSFI LÓPEZ \\ Departamento de Filología Española \\ Universidad Autónoma de Barcelona \\ yasminayousfi9@gmail.com
}

\begin{abstract}
RESUMEN
Numerosos españoles republicanos continuaron desplegando una férrea y activa lucha contra el fascismo desde el exilio. Su compromiso se manifestó a través de una intensa actividad intelectual focalizada, frecuentemente, en los derroteros de la Segunda Guerra Mundial. Las revistas culturales fueron medios de expresión muy habituales. En Chile, una de las más significativas -desconocida aún- fue España Libre (1942-1943), un «semanario republicano español» que, a través de múltiples crónicas y artículos, ofrecía un profuso seguimiento del curso de la guerra y, hoy día, refleja las preocupaciones artísticas, políticas, estéticas y filosóficas que, desde el exilio, suscitaba el contexto bélico internacional.
\end{abstract}

Palabras clave: Exilio republicano, España, Chile, publicaciones periódicas, Resistencia, antifascismo.

\section{Resistance from Exile: Chile and the Journal España libre}

\begin{abstract}
Many Spanish republicans carried on with a fierce and active struggle against fascism from their exile. They exhibited their commitment through an intense intellectual activity, usually focused on the developments of the Second World War. Cultural journals were a habitual way of communication. In Chile, one of the most significant journals was España Libre (1942-1943), which remains still unknown. This so-called «Spanish republican journal» offered a profuse coverage of war course, by means of multiple articles and reports. Nowadays, it reflects the artistic, political, aesthetic and philosophical concerns that the international armed conflict aroused on the exile community.
\end{abstract}

Keywords: Republican exile, Spain, Chile, periodicals, Resistance, anti-fascism.

Tras la derrota militar de la Segunda República española en 1939, la mayoría de aquellos intelectuales que habían participado activamente en el proceso cultural que conformó la denominada Edad de Plata (Mainer 1981), fueron abocados a un exilio que, en muchos casos, ni siquiera la experiencia de retorno a España pudo dirimir. 
La posición política de los exiliados republicanos españoles cubría un heterogéneo espectro ideológico que confluía en un punto determinante: el antifascismo. Desde el exilio, numerosos españoles continuaron manteniendo una actitud comprometida con los ideales republicanos desplegando una férrea y activa lucha contra el fascismo. Apunta el filósofo republicano español exiliado en México, Adolfo Sánchez Vázquez, en sus Recuerdos y reflexiones del exilio, específicamente en el ensayo «Fin del exilio y exilio sin fin», que, a pesar de que el retorno a la patria se experimente físicamente, el sentimiento exílico es implacable:

Y entonces el exiliado descubre con estupor primero, con dolor después, con cierta ironía más tarde, en el momento mismo en que objetivamente ha terminado su exilio, que el tiempo no ha pasado impunemente, y que tanto si se vuelve como si no se vuelve, jamás dejará de ser un exiliado (Sánchez 1999: 47).

Continúa afirmando Sánchez, no obstante, que, si bien el exiliado se ve condenado a serlo para siempre, condición vista no solo como suma de pérdidas y desilusiones, sino también como la confluencia de dos tierras, de dos raíces y de dos esperanzas, es decisiva la actitud que mantiene a lo largo de su vida: «Lo decisivo es ser fiel -aquí o allí- a aquello por lo que un día se fue arrojado al exilio. Lo decisivo no es estar -acá o allá- sino cómo se está» (Sánchez 1999: 27). El compromiso con determinados valores republicanos, manifestado en el desarrollo de una labor intelectual constante en los países de acogida, es el que define la importancia del «cómo se está» al que se refiere el filósofo. Este compromiso se manifestó más fervientemente durante los primeros años de exilio, coincidiendo con el desarrollo de la Segunda Guerra Mundial, cuando la posible derrota del fascismo podía significar la caída del régimen franquista en España. Desde el destierro, los españoles desplegaron una significativa campaña antifascista a través, entre otros, de la creación de medios de comunicación. Las revistas culturales fundadas durante la década de los cuarenta en el exilio, por ejemplo, se erigen como verdaderos organismos de resistencia porque, más allá de abordar el nuevo panorama local/nacional, se centran en el continental, panamericano y paneuropeo, participando, así, de las redes transnacionales más influyentes, a nivel cultural e intelectual, del contexto bélico internacional.

1 Según el «informe Neruda», cuyos datos reprodujo la prensa chilena de la época como El Mercurio, entre refugiados y algunos chilenos que combatieron en las Brigadas Internacionales, el Winnipeg llevaba a bordo 2.004 personas. No obstante, se trata de una cifra aún especulativa, que contrasta con los datos de la investigación de Jaime Ferrer Mir, Los españoles del Winnipeg (1989), donde la lista recoge un total de 2.300 tripulantes, probablemente todavía incompleta (Gálvez 2012: 129-130). Después del Winnipeg, siguieron llegando centenares de españoles republicanos a Chile en los vapores Formosa, Reina del Pacífico, Marsilia y Órbita. Una vez que estos atracaban en Argentina, los exiliados viajaban en el Ferrocarril Trasandino que conectaba Argentina con Chile. De esta diáspora es paradigmática la llegada de varios intelectuales, pertenecientes al grupo de los diecisiete refugiados en la Embajada chilena de España tras la victoria del franquismo, creadores durante los meses de asilo -de noviembre de 1939 a junio de 1940- del periódico El Cometa y de la revista antifascista Luna. Entre ellos se encontraban Edmundo Barbero, Santiago Ontañón, Pablo de la Fuente, Antonio Aparicio o Antonio de Lezama, todos exiliados en Santiago de Chile. 
Por las múltiples afinidades culturales, los países latinoamericanos fueron los grandes receptores de exiliados españoles a partir de 1939. Respecto a Sudamérica, Argentina, Chile y Uruguay son los principales focos de asilo. La mayoría de los refugiados que llegaron a Chile, el país que nos ocupa, lo hicieron a bordo del Winnipeg ${ }^{1}$, el barco carguero que zarpó desde Francia el 4 de agosto de 1939 hasta Valparaíso gracias al apoyo y el compromiso del gobierno chileno y a las gestiones de Pablo Neruda, Cónsul Especial para la Inmigración Española, delegado en París. La campaña que desplegó el gobierno del Frente Popular de Pedro Aguirre $\mathrm{Cerda}^{2}$, que consideraba la mano de obra española como un factor determinante para el desarrollo de Chile, despertó, desde la llegada del Winnipeg, la solidaridad del pueblo chileno con los españoles, propiciando, específicamente en el campo cultural, que la trayectoria profesional de periodistas, críticos, escritores, pintores, directores teatrales, actores, músicos, dramaturgos y escenógrafos españoles se viera continuada durante su exilio con éxito ${ }^{3}$. Francisco Caudet, que ha hablado acerca de la desconexión de los exiliados con respecto a la realidad de sus países de acogida, causa del «efecto distorsionador de la realidad», toma como referencia el éxito de la editorial Cruz del Sur, fundada por Arturo Soria en Santiago, contrastándolo con el fracaso de la editorial Séneca en México, para afirmar que este «efecto distorsionador de la realidad» no se dio en Chile porque supieron «atender debidamente tanto a la producción cultural americana como a la española» (Caudet 1997: 497). Esta reflexión puede extrapolarse a otros ámbitos culturales como, por ejemplo, las artes escénicas, donde la destreza de Margarita Xirgu por crear repertorios en los que aunaba teatro español y chileno garantizaba una positiva recepción del público santiaguino. Esta situación fue posible porque los intelectuales exiliados en Chile, como explicaba José Ricardo Morales (1915-2016), dramaturgo que llegó a bordo del Winnipeg con apenas 23 años, «al dar origen en el país adoptivo a diferentes actividades o conocimientos, de los que carecía, pudimos hacer de él nuestra nación, no por haber nacido en su territorio, sino por hacer hecho nacer en este cuanto pudimos y le debíamos» (Morales 2012: 221). No obstante, el exilio intelectual en Chile es un tema que contiene aristas aún por estudiar. Si bien existen varios trabajos sobre el desarrollo cultural de los exiliados republicanos en Chile, estos, o tienden a hacer un análisis general de la cuestión ${ }^{4}$, o están dedicados a la pro-

${ }^{2}$ Como indica Fabián Almonacid Zapata en «Españoles en Chile: relaciones de la colectividad frente a la República, Guerra Civil y Franquismo», hacia 1938, con la llegada al poder de Pedro Aguirre Cerda con el Frente Popular, aumentó la presencia pública de los republicanos españoles que vivían en Chile y se estrecharon los lazos con el equivalente gobierno español: «El inicio del gobierno de Aguirre Cerda significó un vuelco en las relaciones de los españoles con la autoridad. El gobierno de Alessandri había estado junto a los nacionales y tolerado la campaña contra la República que estos realizaban. Con las nuevas autoridades esto llegaba a su fin, aunque dado el fuerte respeto a las libertades democráticas, los españoles nacionales no tuvieron problemas para seguir, con menos notoriedad, sus actividades» (Almonacid 2004: 180).

3 Apunta la investigadora Dora Schwarzatein que la emigración republicana a Chile fue, no obstante, la de menor número de intelectuales y profesionales de toda América, «con una alta proporción de artesanos, como zapateros, herreros y carpinteros» (Schwarzstein 2001: 40).

${ }^{4}$ Merece especial atención el estudio introductorio de España 1939: los frutos de la memoria. Disconformes y exiliados. Artistas e intelectuales españoles en Chile (1939-2000), compuesto por dos 
ducción intelectual de las figuras más representativas; el tema de la producción cultural e intelectual dirigida explícitamente a un público exiliado, como es el caso de ciertas publicaciones periódicas relevantes, apenas ha sido abordado. Es necesario, por tanto, comenzar a tratar la presencia republicana en Chile desde enfoques metodológicos que subrayen la heterogeneidad del fenómeno del exilio cultural -prácticas, ámbitos de actuación, impacto, recepción- a partir de un análisis de fuentes primarias, principalmente hemerográficas.

Uno de los ámbitos más activos durante los primeros años del exilio en Chile fue el periodismo, no solo por las colaboraciones de un buen número de españoles en la prensa chilena, sino también gracias a la creación de publicaciones periódicas propias como República Popular (1940), España Libre (1942), Iberia, Mundo Ibérico (1943), o La libertad de España (1945), que actuaban, como hemos anunciado, como organismos de resistencia antifascista desde el exilio. En el presente artículo nos centraremos en la publicación más sólida, España Libre, un «periódico republicano español $»^{5}$ fundado en 1942 en Santiago de Chile por varios españoles republicanos exiliados en el país andino, que sobrevivió hasta mediados de 1943, dejando un total de treinta y seis números. Uno de los objetivos principales que persigue España Libre -que, como el resto de publicaciones citadas hasta el momento no ha recibido la atención de la crítica ${ }^{6}$-, es informar acerca de la situación de España en el marco de la campaña militar y la política antifascista de los aliados; por ello, a través de múltiples crónicas y artículos de opinión repartidos en diferentes secciones, esta revista ofrece un profuso seguimiento del curso de la Segunda Guerra Mundial y de la actualidad internacional. Además, la sección «Arte y literatura», nutrida de artículos de destacados intelectuales del exilio español en Chile, promotores del semanario, refleja las preocupaciones artísticas, políticas, estéticas y filosóficas suscitadas por el contexto bélico internacional y sostiene la célebre máxima de Sánchez Vázquez ya mencionada: «lo importante no es estar -acá o allá-, sino cómo se está».

La revista, de cuatro páginas inicialmente, con medidas 38 por $53 \mathrm{~cm}$ y precio de 1 peso, giraba alrededor de tres ejes temáticos: la Segunda Guerra Mundial, la España franquista y el exilio republicano español, tanto chileno como americano. El equipo de redacción, formado por intelectuales como Vicente Mengod, Antonio R.

capítulos, a cargo de Carmen Norambuena y Cristian Garay, y de Francisco Caudet, editado por la Universidad de Santiago de Chile y el Centro Cultural de España en Chile en 2002. Esta obra reconstruye las biografías de los intelectuales españoles exiliados más importantes en el contexto de la cultura chilena.

${ }^{5}$ La periodicidad durante 1942 fue quincenal hasta abril de 1943, cuando pasa a ser semanal.

${ }^{6}$ Encontramos tres fuentes de referencia que recogen datos sobre España libre: ANDÚJAR, Manuel (1976): «Las revistas culturales y literarias del exilio en Hispanoamérica» en El exilio republicano de 1939 III. Revistas, pensamiento, educación, José Luis Abellán (ed.), pp. 91-93. Madrid: Taurus; ABELLÁN, José Luis y MONCLÚS, Antonio (1989): El pensamiento español contemporáneo y la idea de América, pp. 578-579. Barcelona: Anthropos, y en el Diccionario biobibliográfico de los escritores, editoriales y revistas del exilio republicano de 1939 II, pp. 268-269. Sevilla: Renacimiento [en prensa]. 
Romera, Pablo de la Fuente, Eleazar Huerta, Antonio de Lezama, Antonio Aparicio y Vicente Salas Viu, encargados principalmente de la sección de Arte y Literatura, contaba con el apoyo de un buen número de colaboradores, exiliados en Chile y externos, que nutrían el resto de secciones. En el número 0, donde se publicaron algunos fragmentos de los artículos que aparecerán en el primer número, aparece una descripción del medio, adjunta al boletín de suscripción. España Libre es definida como «el periódico republicano español en Chile» que funcionará como «portavoz y vínculo de relación de cuantos desean la libertad de España y que nuestra causa sea considerada en el Mundo con iguales derechos que las de otras democracias sojuzgadas por el fascismo» (EL 1942, 0) ${ }^{7}$.

España Libre contaba con varios espacios que informaban acerca del conflicto bélico internacional. Durante 1942, surge «Marcha de la guerra», una sección para la que el Teniente Coronel del Barrio -Enrique Jurado Barrio, combatiente durante la guerra civil española y exiliado en Uruguay- elaboraba quincenalmente un informe muy detallado, con el apoyo de infografías, sobre los avances de la contienda, prestando especial atención al desarrollo de la Batalla de Stalingrado (agosto 1942 - febrero 1943). Información más genérica, proveniente de agencias de prensa, se ofrecía en la sección «Notas y noticias», constituida por un conjunto de breves que orientaban acerca de aspectos muy específicos del conflicto internacional cuya información aparecía clasificada por países. Por ejemplo: «Francia. La represión de Pétain», «EE.UU. Comités que se forman», «Colombia. Una petición de unidad de los republicanos» (EL 1942: 1). En ella, era frecuente encontrar también varias notas sobre las relaciones políticas, económicas y propagandísticas entre España y Alemania bajo epígrafes como «El franquismo al servicio del eje» (EL 1942: 3 ) o «Preparativos nazis en España» (EL 1942: 7).

No obstante, son los géneros de opinión los que de manera más analítica hablaban del curso de la Segunda Guerra Mundial, en términos socio-políticos. Además de los editoriales y las heterogéneas colaboraciones, destaca la columna «Rueda el mundo» de ELE, firma incondicional a lo largo de los dos años de vida de la revista. ELE interrelacionaba los diferentes temas de actualidad en los que se focalizaba cada número a partir de unas pinceladas críticas sobre política internacional. A modo orientativo, citaremos algunos de sus titulares de carácter temático: «El eje y sus amigos», «El discurso de Churchill» (EL 1942: 1), «El proceso de Riom», «Suiza y Andorra» (EL 1942: 2), «Los misioneros de Nueva Guinea», «El secreto del Aconcagua» (EL 1942: 3), «Los nazis y España», «Propaganda nazi» (EL 1942: 7), «China y su guerra» (EL 1942: 10), «Negrín y la República», «De Moscardo a Mussolini» (EL 1942: 18), «Tánger y el franquismo», «La furia de Stalingrado», «Iraq en guerra» (EL 1943: 19), «Polonia a contrapelo» (EL 1943: 25), «Mussolini y su rey», «Roma-Madrid» (EL 1943: 33). Veamos un ejemplo significativo para apreciar el tono incisivo y la precisión irónica en la exposición de las ideas: «La ayuda a Alemania», escrito con motivo de la postura de «beligerancia moral», adoptada por

${ }^{7}$ Los textos extraídos de España Libre se citarán señalando el nombre de la revista (se utilizarán las siglas $E L$ ), seguido del año de publicación y el número de la revista. 
España a finales de junio de 1942, y la consecuente formación de la «División Azul» para luchar contra la URSS:

El mismo Hitler ha sido quien ha propuesto a su satélite en Francia, el señor Laval, que le ayude de preferencia enviándole obreros especializados para sus fábricas. Lo ha hecho público Laval en un discurso de modo que la fuente es intachable. A Hitler, pues, ya no le interesan los cruzados antibolcheviques: lo que quiere son esclavos. [...] ¿Es neutral la España franquista? Sería pintoresco oír el juicio del Embajador británico en Madrid, a la luz de estas realidades (EL 1942: 9).

Respecto a la opresión política, económica y social de la España de posguerra, la revista contaba con firmas como las de Valentín de Pedro, periodista tucumano que desarrolló la mayor parte de su carrera periodística en la España de preguerra, que colaboró con artículos de firme tono de denuncia como «En las cárceles de España» (EL 1942: 1), donde da cuenta de las condiciones infrahumanas de las cárceles franquistas; Julio Álvarez del Vayo, Ministro de Estado en tiempos de Largo Caballero, con textos como «Tres años de Franco», un «artículo mortuorio», como él mismo lo define, «no por una esperanza optimista sobre un rápido colapso del Estado títere construido por Italia y Alemania», sino por la decadencia misma del régimen franquista, «uno de los más incapaces e impopulares regímenes que jamás haya existido en la larga historia de la tiranía» ( $E L$ 1942: 7), o el Embajador de la República en el Exilio y embajador en Chile durante los últimos años de la República, Rodrigo Soriano, que colaboraba con frecuentes publicaciones de tono muy enfático, entre las que destacamos su carta al embajador de los Estados Unidos en Chile, Claude Bowers, titulada «Trágica situación de los refugiados en África» y publicada en febrero de 1943 (EL 1943: 20), donde reclama abiertamente la ayuda de EEUU en la mediación con Francia para la liberación de los refugiados de los campos de concentración en el norte de África.

Asimismo, España Libre solía reproducir textos aparecidos en medios nacionales e internacionales que habían influido de manera significativa en la opinión pública. Es destacable la publicación del polémico reportaje «Hambre y espanto en la España franquista», aparecido en el Saturday Evening Post de Londres, basado en las vivencias del periodista James Wood Johnson y del doctor Alexis Carrel en su visita a la «mísera» España de posguerra (EL 1942: 10). En esta línea, conviene subrayar un editorial del diario chileno La Hora, publicado en marzo de 1942 (EL 1942: 2), en respuesta a la dura campaña desplegada por los diarios más conservadores santiaguinos como El Mercurio, El diario ilustrado o El Imparcial, voceros de la derecha chilena que, desde las primeras negociaciones de Pablo Neruda con la creación del Comité Chileno de Ayuda a los Refugiados Españoles $(\mathrm{CChARE})^{8}$, se mostró contraria a la acogida de inmigrantes españoles y presionó

${ }^{8}$ La CChARE fue creada bajo los auspicios del Frente Popular de Chile. Su secretario general, José M. Calvo, ayudó a gestionar el viaje desde Chile. 
incesantemente al gobierno de Aguirre Cerda para derribar la política de asilo de los refugiados a Chile?. Con ellos, estaba el sector franquista de la colectividad de españoles que vivían en Chile, que había adoptado poder tras la guerra civil, gracias al respaldo de la Embajada. A pesar de que la llegada de los exiliados contribuyó a mantener el sentimiento republicano, «ya hacia 1940 se observa una mayor organización y red de influencia del sector franquista» (Almonacid 2004: 184).

Por otra parte, el considerable espacio dedicado a las noticias sobre la acción republicana en el exilio alimenta el deseo de recuperación de la patria perdida. España Libre mantiene un discurso optimista de unidad y solidaridad en pro de la democracia y la libertad de España, una suerte de llamamiento al compromiso y la resistencia de los exiliados, independientemente de su filiación política. Por ello, la revista reproducía frecuentemente discursos y manifiestos promovidos, entre otros, por dirigentes republicanos en el exilio. A partir del número 16, a finales de 1942, este tipo de publicaciones se reunieron en el suplemento político-cultural «Textos y Documentos», motivado por la positiva recepción de la revista, que mantenía el objetivo de ofrecer un detallado seguimiento de la lucha republicana. En él, encontramos una notable pluralidad temática. Por ejemplo, el número 25 recogía esta variedad de noticias: «Se constituyó un grupo de mujeres españolas para ayudar a las democracias», «Negrín felicita a la URSS», «Los republicanos en Londres se dirigen a su correligionarios», «Una carta del comité regional de la CNT de México», «Un manifiesto de los españoles republicanos en Chile» (EL 1943: 25).

Igualmente es necesario subrayar la importancia de «Literatura y artes», una sección que pasó de ocupar una página a convertirse también en un suplemento. Entre su contenido, cobraba especial significación aquel que, por su carácter comprometido, intentaba recuperar el discurso cultural y literario republicano, truncado con la guerra civil, tendiendo puentes con la intelectualidad exiliada. Un ejemplo de ello son los homenajes a poetas como Antonio Machado o Miguel Hernández, que incluían la reproducción de fragmentos muy significativos de sus obras como algunas lecciones de Juan de Mairena o la «Canción del esposo soldado» de Hernández. La literatura de la guerra civil también era un tema muy recurrente. Los números 4 y 5 ,

${ }^{9}$ Los argumentos que aducía la facción política más conservadora del país se basaban en el alto coste que supondría para el gobierno la acogida de los inmigrantes o la invasión de los comunistas en el país. Cabe añadir que el viaje del Winnipeg fue financiado principalmente por el Servicio de Emigración de los Republicanos Españoles (SERE), organismo de auxilio creado en París en 1939 y adscrito al equipo de gobierno de Juan Negrín y por la Federación de organizaciones Argentinas pro Refugiados Españoles (FOARE), dirigido por el argentino Ricardo M. Setaro. La operación fue gestionada por el canciller chileno Abraham Ortega y Pablo Neruda. En julio de 1939, se discutieron en la Cámara de Diputados de Chile los acuerdos del traslado con el SERE y la FOARE: «La oposición se enfrentó en la Cámara de Diputados con tal virulencia a esa expedición, que estuvo a punto de causar una grave crisis política. El canciller Abraham Ortega, debido a esa polémica, presentó la dimisión que el Presidente, con buen criterio, no aceptó. El Gobierno, que llegó en esos momentos a reconsiderar la decisión de permitir la inmigración de republicanos, mandó a Pablo Neruda, cuando ya estaba a punto de partir de Francia el Winnipeg, la orden, que no atendió, de esperar» (Norambuena y Garay 2002: 17). Para más información, véase también el capítulo «Pablo Neruda y el Winnipeg» de Winnipeg. Testimonio de un exilio (2012) de Julio Gálvez, pp.59-101. 
unidos en un número extraordinario en conmemoración del XI aniversario de la República, por ejemplo, incluyeron una selección de poemas de Arturo Serrano Plaja, «Los soldados», Rafael Alberti, «Galope», Antonio Aparicio, «Al coronel modesto», o Luis Pérez Infante, «Canto continental» ${ }^{10}$. El espíritu de resistencia se manifestaba, además, en textos que describían la trayectoria poética en el exilio de escritores reconocidos como Rafael Alberti (EL 1942: 3), Pedro Salinas (EL 1942: 14) o Juan Ramón Jiménez (EL 1942: 16); también, en colaboraciones puntuales como las de José Bergamín, «El santo oficio del escritor» (EL 1943: 26), del poeta ecuatoriano Jorge Carrera Andrade, «Poesía de la guerra y de la muerte» (EL 1943: 27), o del intelectual mexicano José Ezequiel Iturriaga, «Sociología falangista» (EL 1943: 29). Asimismo, cabe destacar la nómina de firmas fijas, integrada por los miembros del comité editorial: Vicente Salas Viu, Pablo de la Fuente o Vicente Mengod ofrecían análisis y reflexiones literarias, Antonio R. Romera, lecciones sobre arte y viñetas satíricas, y Eleazar Huerta, recomendaciones editoriales ${ }^{11}$. A partir de abril de 1943, la sección cuenta con la columna de José Ferrater Mora titulada «Cuestiones españolas», donde el filósofo redefinía el mito de «las dos Españas» desde una perspectiva contemporánea.

Pese a la buena recepción del público lector, evidenciada en la creación de dos suplementos y en la reducción de su periodicidad, el paso de quincenal a semanario en abril de 1943, España Libre dejó de publicarse en agosto de ese mismo año debido al cese de financiación, motivado por las diferencias políticas que dividieron el Centro Republicano Español en Chile, organismo al que estaba emparentada la publicación. Su gran virtud, como principal cabecera republicana del exilio chileno, fue aunar coherencia discursiva, volcada en una línea editorial marcada por la pluralidad de pensamiento republicano en pro de la lucha antifascista, con calidad periodística, tanto en información como en opinión, dotada de una ferviente actualidad y de un espíritu esperanzador.

Destaca Francisco Caudet la importancia de la palabra con «función terapéutica» para verbalizar experiencias del pasado (Caudet 2002: 23) al valorar positivamente el agitado diálogo que los exiliados mantenían notablemente en las tertulias ${ }^{12}$.

10 Tanto Serrano Plaja, como Aparicio o Pérez Infante se habían exiliado en Santiago de Chile. El primero estuvo en la capital durante un año, hasta que, a finales de 1941, se traslada junto a su mujer a Buenos Aires; Aparicio abandonará Chile en 1949, tras ocho años de estancia, y Pérez Infante se instalaría en Montevideo, ciudad en la que falleció, en 1946.

11 Estos exiliados, como dirían Carmen Norambuena y Cristian Garay, conforman «un grupo social interrelacionado» cuya pervivencia en el ámbito cultural chileno, se debe fundamentalmente a su «asimilación radical al medio local» (Norambuena y Garay 2001: 223) colectivamente.

12 En Santiago de Chile, el espacio de reunión de españoles republicanos más emblemático fue el Café Miraflores, abierto por el escritor Pablo de la Fuente y su mujer, Mina Yánez. Entre sus peculiaridades, destacaban las caricaturas que el escenógrafo Santiago Ontañón y el ilustrador Antonio Rodríguez Romera habían realizado para adornar el local. José Ricardo Morales subraya que los temas recurrentes en las tertulias del Miraflores se forjaban sobre una evocación del pasado que, en el caso de algunos exiliados, era un recurso excesivamente manido, lo que los convertía en «personajes trágicos»: «De ahí las interminables tertulias mantenidas entre ellos, dedicadas a su participación en tal o cual batalla o a la permanencia en determinado campo de concentración. Esos recuerdos, -y únicamente 
Esta función terapéutica de la palabra oral puede extrapolarse fácilmente a la palabra escrita, dada en el intercambio entre periodistas y lectores donde se verbalizan los recuerdos, el compromiso y la esperanza. Si bien la consolidación de la trayectoria intelectual del colectivo de exiliados en Chile se debe, como ya hemos indicado, al afán de adaptación al medio chileno, por lo que se eluden, al menos de manera recurrente, temas relacionados con la «España peregrina», la apreciación de que la obra americana de los exiliados sirvió como remedio del destierro (Norambuena y Garay 2001: 223), pierde valor en el caso de las publicaciones periódicas como España Libre. En ella, a pesar de que en ocasiones se interpela al lector chileno solidario con la causa republicana y se ofrece una información internacional dirigida a cualquier público, el destinatario indiscutible es el colectivo exiliado republicano interesado no solo por realidad de la España de posguerra o por el vasto espacio del exilio americano, sino también por el devenir de Europa, ya que la derrota del fascismo podía significar el comienzo del fin del exilio. Sin embargo, el compromiso, esa actitud que tanto defendía España Libre, no se manifestaba de manera idealista, pues el franquismo, desde la España exiliada y disidente, no se identificaba especularmente con el nazismo, sino que, en términos coyunturales, se concebía como el reflejo refractado de este. Temas relacionados con la posibilidad de retorno al sistema monárquico o con la aparente "sordina» con la que se manifestaba la guerra mundial en España, como apuntó Eleazar Huerta en uno de sus artículos, «Guerra Mundial pero Guerra civil», propiciaban esta percepción:

Y yo afirmo, desde mi invariable punto de vista, que España no es neutral en esta guerra. Dejando aparte el hecho de que ninguna nación lo es, en definitiva, menos puede serlo la nuestra, en donde empezó la contienda. Contienda civil y universal desde entonces, en la que nos metieron de cabeza los señoritos españoles, para que en nuestras capitales se ensayaran los aviones de picada y cuanto requería el ensayo general de la tragedia que hoy se representa en el gran teatro del mundo. En nuestra patria ni siquiera hay una tregua, puesto que la persecución de los «rojos» no cesa. La guerra sigue, si bien con sordina. Si las circunstancias de Europa la manifiestan violentamente otra vez, ellos seguirán del lado fascista, donde estuvieron y están. Nosotros, los republicanos, en el nuestro, o sea enfrente, con las democracias, con la Democracia (Huerta 1942:16).

Desde el exilio, la tragedia de la guerra tiende a entenderse desde una perspectiva global, de tal manera que la liberación de España se prevé como un proceso pedregoso que no depende exclusivamente del curso de la Segunda Guerra Mundial sino, principalmente, de la persistencia, la solidaridad y la unión de todos aquellos

\footnotetext{
esos- semejaban mantenerlos vivos al conservar en su memoria la brasa luminosa del pasado, convirtiéndolos en personajes trágicos, pues semejantes a los del drama antiguo le daban cierto sentido retroactivo a su propio vivir, representándose de continuo la injusticia sufrida y las acciones emprendidas por ellos para contrarrestarla» (Morales 2012: 224).

13 * Materiales consultados en el fondo hemerográfico de la Biblioteca Nacional de Chile (ubicación PCH 11655).
} 
que sufrieron el destierro: de seguir manteniéndose fieles, al fin y al cabo, «a aquello por lo que un día se fue arrojado al exilio», como decía Sánchez Vázquez, independientemente de estar en América, en Europa o en España, independientemente de estar «acá o allá». Y el número de aquellos que optaron por resistir, como subrayaba Vicente Salas Viu en «La tragedia de los desarraigados», un artículo publicado en el número 2 de España Libre, era «infinito»:

Hay quienes han sido puestos en la linde de su vida por la catástrofe en que el mundo ahora se debate y, asomados a ese término, lo han visto como tal. Nada queda tras él. Los más caros ideales, el sostén de su vida se hallan en ruinas. No hay senda que seguir ni por parte alguna posibles esperanzas. Otros, llegados al mismo trance, en su cruel angustia, tras el aparente acabose de todo, alcanzan a ver como en confusa perspectiva los contornos de aquello a lo que tanto han sacrificado. Porque el número de estos es mayor, lo es también el de mártires que el de suicidas en nuestro tiempo. Infinito, el de quienes sin pertenecer ni a una ni a otra categoría, encontramos entre las quiebras de nuestro espíritu estímulo para esperar una vida que devuelva su sentido a la hasta ahora vida (Salas 1942: 2).

\section{Referencias bibliográficas:}

ABellán, José Luis y Monclús, Antonio (1989): El pensamiento español contemporáneo y la idea de América. Barcelona: Anthropos.

ALMONACID, Fabián (2004): «Españoles en Chile: relaciones de la colectividad frente a la República, Guerra Civil y Franquismo». Revista Complutense de Historia de América 30: 149-185.

ÁlVAREZ Del VAYO, Julio (1942): «Tres años de Franco». España Libre 7.

ANDÚJAR, Manuel (1976): "Las revistas culturales y literarias del exilio en Hispanoamérica» en José Luis Abellán (ed.): El exilio republicano de 1939, III. Revistas, pensamiento, educación , pp.88-90. Madrid: Taurus.

CARrel, Alexis y WoOD JoHnson, James (1942): «Hambre y espanto en la España franquista». España Libre 10.

CAUDET, Francisco (1997): Hipótesis sobre el exilio republicano de 1939. Madrid: Fundación Universitaria Española.

- (2002): «Estudio preliminar» en Carmen Norambuena y Cristian Garay (eds.): España 1939: los frutos de la memoria. Disconformes y exiliados. Artistas e intelectuales españoles en Chile (1939-2000), pp. 14-25. Santiago de Chile: Universidad de Santiago Chile/Centro Cultural de España en Chile.

DE PEDRO, Valentín (1942): «En las cárceles de España». España Libre 1.

ELE (1942): «La ayuda a Alemania». España Libre 9.

(1942): «Un editorial de La Hora. 'Sobre los refugiados españoles'». España Libre 2.

(1942-1943): España Libre 1-36. Santiago de Chile ${ }^{13}$.

GÁlveZ, Julio (2012): Winnipeg. Testimonio de un exilio. Santiago de Chile: Cal Sogas.

HUERTA, Eleazar (1942): «Guerra Mundial pero Guerra civil». España Libre 16.

MAINER, José Carlos (1981): La Edad de Plata (1902-1939). Ensayo de interpretación de un proceso cultural. Madrid: Cátedra.

MoraleS, José Ricardo (2012): Obras completas II. Ensayos. Valencia: Institució Alfons el Magnànim. 
Norambuena, Carmen y GARAY, Cristian (2002): España 1939: los frutos de la memoria. Disconformes y exiliados. Artistas e intelectuales españoles en Chile (1939-2000). Santiago de Chile: Universidad de Santiago Chile/Centro Cultural de España en Chile.

SALAS VIU, Vicente (1942): «La tragedia de los desarraigados». España Libre 2.

SÁNCHEZ, Adolfo (1999): «Fin del exilio y exilio sin fin» en Recuerdos y reflexiones del exilio, pp. 45-47. Sant Cugat del Vallès: Associació d'Idees/GEXEL.

SchwarZATEIN, Dora (2001): Entre Franco y Perón. Memoria e identidad de exilio republicano español en Argentina. Barcelona: Crítica.

SORIANO, Rodrigo (1943): «Trágica situación de los refugiados en África». España Libre 20.

VV.AA. (en prensa): Diccionario biobibliográfico de los escritores, editoriales y revistas del exilio republicano de 1939 II. Sevilla: Renacimiento. 